This document was prepared in conjunction with work accomplished under Contract No. DE-AC09-96SR18500 with the U.S. Department of Energy.

This work was prepared under an agreement with and funded by the U.S. Government. Neither the U. S. Government or its employees, nor any of its contractors, subcontractors or their employees, makes any express or implied: 1 . warranty or assumes any legal liability for the accuracy, completeness, or for the use or results of such use of any information, product, or process disclosed; or 2 . representation that such use or results of such use would not infringe privately owned rights; or 3 . endorsement or recommendation of any specifically identified commercial product, process, or service. Any views and opinions of authors expressed in this work do not necessarily state or reflect those of the United States Government, or its contractors, or subcontractors. 
WSRC-TR-2005-00437

\title{
Evaluation of a New Pinch Resistance Test Method
}

\author{
By
}

P.S. Korinko

G. H. Fisher, Jr

S.R. Howard

September 2005

\section{Westinghouse Savannah River Company} Aiken, SC 29808

Prepared for the U.S. Department of Energy under Contract DE-AC09-96SR18500 
Evaluation of a New Pinch

Resistance Test Method 
MST

MATERIALS SCIENCE and TECHNOLOGY

$\begin{array}{ll}\text { Keywords: } & \text { Stainless steel } \\ & \text { Fill Stems } \\ & \text { Pinch welds } \\ \text { Retention: } & \text { Permanent }\end{array}$

\title{
Evaluation of a New Pinch Resistance Test Method
}

\author{
By \\ P.S. Korinko \\ G. H. Fisher, Jr \\ S.R. Howard
}

Materials Compatibility and Welding Technology Group

ISSUED: September 2005

SRNL SAVANNAH RIVER NATIONAL LABORATORY, AIKEN, SC 29808 Westinghouse Savannah River Company

Prepared for the U.S. Department of Energy under Contract DE-AC09-96SR18500 
Resistance Test Method

Document: WSRC-TR-2005-00437

Title: $\quad$ Evaluation of a New Pinch Resistance Test Method APPROVALS

Materials Compatibility and Welding Technology

\section{$9 / 27 / 2005$}

S.R. Howard, Author

Date

Materials Compatibility and Welding Technology

By concurrence electronic signature

G. H. Fisher, Jr., Author

9-29-2005

Tritium Support, Instrument and Examination Section

E.A. Clark, Technical Reviewer

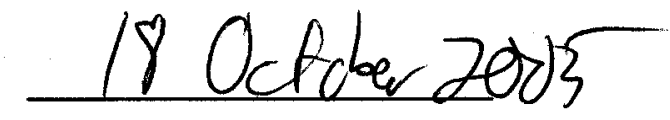

Materials Compatibility and Welding Technology

Date

Date

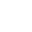




\title{
Evaluation of a New Pinch Resistance Test Method
}

\begin{abstract}
The existing method of pinch resistance testing before the pinch weld is made is primarily useful for recognizing electrode contact consistency. An improved test method is proposed that would provide recognition capabilities for other off-normal welding conditions. Such recognition could be used to prevent inadequate pinch welds. The new resistance testing method uses the Medar weld controller to pass a significantly higher current than that used in the existing method. Several tests were conducted to evaluate the effect of the higher test current on pinch welds and to evaluate the proposed test method's capabilities to detect oxide film, defective electrodes, loose electrodes and conductors, internal stem defects and atypical tubing hardness. These tests showed that the new method has more pronounced indicators than the existing method. These more easily noticeable indicators make the new method attractive as a replacement for the existing method.
\end{abstract}

\section{Background}

The existing preweld pinch resistance test uses a low current and voltage and does not clearly indicate subtle variations in welding resistance conditions. A new resistance test method using a higher current was suggested, which has the potential to detect subtle anomalies. A series of tests were conducted using the existing and the proposed resistance tests, to determine if specific welding set up anomalies could be detected. Various electrical resistance and material changes were introduced to the weld system. These changes simulated problem-causing conditions that can occur during production. The indicators of each anomaly for the existing and proposed tests were compared.

The measure of resistance is the primary test indicator for setup anomalies. Resistance is calculated from the RMS voltage measured after applying a fixed current. The existing test method applies about 2.4 Amps with a resultant voltage of about 0.008 Volts. The proposed new method uses about 1200 Amps with a resultant voltage of about 0.200 Volts. The higher current and voltage provides better indicator resolution without adversely affecting areas that will be welded later.

The resistance as measured by the existing method uses probes which are inserted into the pinch weld electrodes, as shown schematically in Figure 1a. It was found that measurements at this location cannot detect resistance changes which are not between the probes. To overcome this limitation, one probe connection was moved to the power lead conductor for some of the tests. The system resistance was changed by placing stainless steel washers, which have higher resistance than the copper contacts, in series with the system current path. Figure 1b shows the probe connection location on the electrode and conductor. The changes to the shape of the 
current and voltage signatures as a result of the probe location are shown for the new method in Figure 2.

\section{Results}

\section{New and Existing Resistance Measurement Methods}

The test responses to various system resistance changes are shown in Table 1. Response variables measured by the existing test method and the new test method are compared. The test current, voltage and calculated resistance are included in this table. The characteristic data signatures for the new method are shown in Figure 3. The corresponding data signatures for the same sample and condition are shown in Figure 4. There are roughly three orders of magnitude difference in the current and voltage values and an order of magnitude difference in resistance values between the existing and new test methods. This makes subtle changes in the measured resistance much more prominent when using the new method. For instance, there was an insignificant measurable difference, approximately $1 \%(\sim 0.03 \mathrm{~m} \Omega)$, in the resistance using the existing method when changing the location of the probe. However, this same change resulted in an indicated change in resistance of about $45 \%(\sim 0.14 \mathrm{~m} \Omega)$ for the new test method. As the system resistance was increased with the addition of the stainless steel washers, the new method indicated an approximate 5\% resistance increase per washer, while the existing method indicated less than a $1 \%$ increase in resistance per washer. These results demonstrate that changes in system resistance can be recognized using both the new and existing methods, but the new method provides a more pronounced indication. These differences are detailed in Table 2.

The issue of sample damage from testing by the new method was addressed. The temperature rise due to the new testing method was examined for evidence of sample damage. The proposed new method current setting of $20 \%$ for one cycle was tested, as were other currents and cycles up to the full weld of $99 \%$ current at 12 cycles. Evidence for metallurgical change as a result of testing was monitored by using a contact thermocouple placed down the tube bore near the test area with the expectation that the final temperature for either method would not exceed a target value of $300^{\circ} \mathrm{C}$. This value was designated as the threshold temperature since atomic migration in stainless steel is known to occur at and above about $350^{\circ} \mathrm{C}$ in short periods of time.

The test results, indicated in Table 3, show that increased numbers of cycles will eventually cause the part to heat above the threshold limit for metallurgical structure changes, but the single cycle at $20 \%$ current does not result in a temperature at which metallurgical structure changes. The tests also indicate that metallurgical structure changes should not occur until the application of at least six cycles at $20 \%$ current. Acceptable thermocouple placement was indicated by an actual 12 cycle weld resulting in a $1000^{\circ} \mathrm{C}$ temperature adjacent to the weld

The test method sensitivity to material and equipment changes was evaluated by testing surface oxidized tubing, internally blocked tubing, loose electrodes, and loose conductor cables. 


\section{Test to Recognize Changes in Material Condition}

A test to recognize changes in the condition of the to-be-welded fill stem material was devised and used selectively on WR-like tubing from the Kansas City Plant (KCP). Tubes having three hardnesses and two cleanliness conditions, for a total of six conditions, were selectively tested. The hardness conditions were i) as received (AR) with a hardness of HRC 24; ii) a partial anneal (PA, $927^{\circ} \mathrm{C}\left[1700^{\circ} \mathrm{F}\right]$ for 20 minutes) with a hardness of HRB 94; and iii) fully annealed (FA, $1149^{\circ} \mathrm{C}\left[2100^{\circ} \mathrm{F}\right]$ for 2 hours) with a hardness of either HRB 32 or 48 depending on furnace run. The surface conditions were also varied by Oakite cleaning $(\mathrm{Cl})$ or oxidizing in an air furnace at $370^{\circ} \mathrm{C}$ for 20 minutes. The oxidized samples exhibited a golden heat tint. These samples were selectively tested in both the clean and oxidized conditions using both the existing and new resistance test methods with the voltage measured across the electrodes and between the electrode and front conductor. The annealed samples exhibited anomalous resistances with the oxidized sample indicated as having a lower resistance than the clean sample $(\sim 5 \%$ for the new method and about $0.5 \%$ for the existing). These anomalous results may be due to the different amounts of cold work caused by the preload deformation, although no additional systematic testing was conducted. The effect of the oxide scale on the external surface of the as-received tubing was a $5 \%$ increase for the new method and about a $0.5 \%$ increase for the existing method. The details for these tests are listed in Table 4.

Oxidized samples in the fully annealed (FA), partially annealed (PA) and as-received (AR) conditions were tested to see if the relative hardness differences could be detected. This information may be useful in identifying stems with atypical hardness. Table 5 contains the details of this portion of the study. It can be seen that the indicated resistance as measured by the new method increases with cold work, i.e., from FA to PA to AR, as expected. The data further show that the partial anneal was only slightly effective at reducing the internal tubing defects that affect resistance. The existing method is unable to detect any type of metallurgical change since the variability of the data falls within the range of the data obtained.

\section{Test to Recognize Loose Electrodes and Conductors}

Neither test method was effective in recognizing a loose electrode. The front electrode was loosened so that it was only finger tight and the resistance was measured using both the new and existing methods measured across the electrodes and across the electrode to the conductor. This condition was not detected by measuring the resistance across the electrodes or between the electrode and conductor. The resistance values are consistent to the second significant figure for both methods.

The new method was most effective in recognizing a loose conductor lead when measuring from across the electrode to the conductor. Neither method was effective when measuring across the electrodes. When measuring across the electrodes, the net resistance change was $1 \%$ or less for both the new and existing measurement methods. In addition, the sign of the change was opposite that expected. However, the indicated resistance was increased by a significant amount when the resistance was measured between the electrode and conductor. The relative increases in resistance for the new and existing methods are 17 and $0.2 \%$ respectively. The details of these test results are listed in Table 6. 


\section{Test to Recognize Internal Stem Defects}

A test was devised to recognize the presence of a conductive contaminant in the stem. A section of 0.060 " diameter drill rod was placed in a piece of AR tubing and the resistance was measured. The existing method was unable to detect this defect while the new method resulted in a measured reduction of the resistance of almost $10 \%$ indicating that this defect could be recognized. These measurements were made with the test leads on the electrodes with the results listed in Table 7.

\section{Conclusions}

A new pinch weld resistance test method is proposed, employing a higher current and different voltage sensing locations than the existing resistance test. Comparison tests of the new and existing tests using mock-ups of several common weld set-up defects revealed:

- Neither test method is able to detect resistance changes that are not between the probe connections. Changing the measurement location from the electrodes to the conductors may help in troubleshooting potential mechanical issues but the electrical signal changes will need further evaluation. The testing conducted in this study measured resistance between one electrode and the front conductor. Recommended probe placement for the production facility would be between the conductors to enable a survey of more of the system.

- Both the existing and new resistance test measurement methods can detect an oxide on the stem surface but the indicator is much more pronounced with the new method.

- Neither test method is effective for recognizing a loose electrode.

- The new test method can detect variations in material hardness. Fully annealed material exhibits a resistance test response about 5\% less than that of the as-received tubing.

- The new test method is more effective than the existing test method for recognizing a loose conductor connection, but it is only effective when measuring from the electrode across the conductor position.

- The new test method can recognize a conductive contaminant in the stem; the existing method cannot.

- Both the existing and new test methods can recognize relative hardness differences between fully annealed, partially annealed and as-received stem conditions.

- The new test method provides better indicator resolution than the existing test method due to its use of higher current and voltage, without adversely affecting areas that will later be welded. 


\section{Acknowledgements}

The authors would like to thank R. Rabun and Defense Programs for supporting this work and would also like to thank S. Collins for her programming expertise and willingness to make test system modifications. They would also like to recognize J.M. Tarpley for suggesting the new method and for his assistance with the PDRD project. 
Evaluation of a New Pinch

Resistance Test Method

Table 1. Resistance measurements for new and existing method

\begin{tabular}{|c|c|c|c|c|c|c|c|}
\hline $\begin{array}{c}\text { Resistance } \\
\text { Change }\end{array}$ & $\begin{array}{l}\text { Current } \\
\text { (A) } \\
\text { w } \\
\text { Existing } \\
\text { Method }\end{array}$ & $\begin{array}{c}\text { Current } \\
\text { (A) w } \\
\text { New } \\
\text { Method }\end{array}$ & $\begin{array}{c}\text { Volts (V) } \\
\text { w } \\
\text { Existing } \\
\text { Method }\end{array}$ & $\begin{array}{c}\text { Voltage } \\
\text { (V) w } \\
\text { New } \\
\text { Method }\end{array}$ & $\begin{array}{c}\text { Resistance } \\
(\mathrm{m} \Omega) \text { w } \\
\text { Existing } \\
\text { Method }\end{array}$ & $\begin{array}{c}\text { Resistance } \\
(\mathrm{m} \Omega) \mathrm{w} \\
\text { New } \\
\text { Method }\end{array}$ & $\begin{array}{c}\text { Location of } \\
\text { Probes }\end{array}$ \\
\hline $\begin{array}{l}\text { Baseline } \\
\text { (nochange) }\end{array}$ & & 1347 & & 0.4150 & & 0.3080 & elec-to-elec \\
\hline $\begin{array}{l}\text { Baseline } \\
\text { (nochange) }\end{array}$ & & 1358 & & 0.4237 & & 0.3124 & elec-to-elec \\
\hline $\begin{array}{l}\text { Baseline } \\
\text { (nochange) }\end{array}$ & & 1357 & & 0.5900 & & 0.4349 & elec-to-cond \\
\hline $\begin{array}{l}\text { Baseline } \\
\text { (nochange) }\end{array}$ & & 1350 & & 0.5885 & & 0.4358 & elec-to-cond \\
\hline $\begin{array}{l}\text { Baseline } \\
\text { (nochange) }\end{array}$ & 2.39 & & 0.00823 & & 3.443 & & elec-to-cond \\
\hline 1 washer & & 1261 & & 0.6160 & & 0.4885 & elec-to-cond \\
\hline 1 washer & & 1263 & & 0.6130 & & 0.4850 & elec-to-cond \\
\hline 2 washers & & 1261 & & 0.371 & & 0.2940 & elec-to-elec \\
\hline 2 washers & & 1250 & & 0.369 & & 0.2950 & elec-to-elec \\
\hline 2 washers & & 1307 & & 0.379 & & 0.2901 & elec-to-elec \\
\hline 2 washers & 2.39 & & 0.00816 & & 3.414 & & elec-to-elec \\
\hline 2 washers & 2.39 & & 0.00818 & & 3.420 & & elec-to-elec \\
\hline 2 washers & 2.39 & & 0.008339 & & 3.489 & & elec-to-cond \\
\hline 2 washers & 2.39 & & 0.008299 & & 3.472 & & elec-to-cond \\
\hline 2 washers & 2.39 & & 0.0082297 & & 3.433 & & elec-to-cond \\
\hline 2 washers & & 1317 & & 0.7035 & & 0.534 & elec-to-cond \\
\hline 2 washers & & 1309 & & 0.7010 & & 0.536 & elec-to-cond \\
\hline 2 washers & & 1304 & & 0.6038 & & 0.489 & elec-to-cond \\
\hline
\end{tabular}


Resistance Test Method

Table 2. Summary resistance changes due to probe location and presence of resistors

$\begin{array}{llllll}\Delta \mathbf{V} & \boldsymbol{\Delta} \mathbf{R} & \mathbf{V}_{\mathrm{c}} / \mathbf{V}_{\mathrm{e}} & \mathbf{R}_{\mathrm{c}} / \mathbf{R}_{\mathrm{e}} & \mathbf{V}_{\mathrm{w}} / \mathbf{V}_{\mathbf{c}} & \mathbf{R}_{\mathrm{w}} / \mathbf{R}_{\mathrm{c}}\end{array}$

$\begin{array}{lllll}\text { Location } & 0.1977 & 0.1355 & 1.504955 & 1.451651\end{array}$

$\begin{array}{lllllll}\text { R due to } 1 ~ W & 0.0253 & 0.0514 & 1.569444 & 1.623041 & 1.042851 & 1.118066\end{array}$

$\begin{array}{lllllll}\text { R due to } 2 \text { W } & 0.0802 & 0.0843 & 1.709744 & 1.7328 & 1.089395 & 1.067625\end{array}$

R due to loc $\quad 0.0001 \quad 0.0260 \quad 1.007344 \quad 1.007609$

$R$ due to $1 \mathrm{~W}$

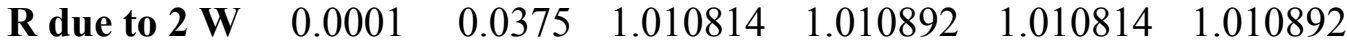

Notes: Location refers to measuring across the electrodes (subscript e) vs. between the electrode and the conductor (subscript c). The last two columns refer to the voltage and resistance measurements due to the washers (subscript w) compared to the measurement at the conductor.

Table 3. Effect of new method on test area as indicated by temperature

\begin{tabular}{|l|l|l|l|l|l|}
\hline \% Current & \multicolumn{1}{|c|}{ Cycles } & $\begin{array}{c}\text { Current } \\
\text { (Amps) }\end{array}$ & $\begin{array}{c}\text { Voltage } \\
(\mathbf{V})\end{array}$ & $\begin{array}{c}\text { Resistance } \\
(\mathbf{m} \Omega)\end{array}$ & $\begin{array}{c}\text { Temperature } \\
{ }^{\circ} \mathbf{C}\end{array}$ \\
\hline 20 & 1 & 1284 & 0.464 & 0.361 & 75 \\
\hline 20 & 5 & 1225 & 0.379 & 0.309 & 220 \\
\hline 20 & 6 & 1220 & 0.383 & 0.314 & 260 \\
\hline 20 & 12 & 1212 & 0.388 & 0.320 & 350 \\
\hline $99 \%(300 \mathrm{v})$ & 12 & 3091 & 0.685 & 0.221 & 1000 \\
\hline 30 & 1 & 1929 & 0.665 & 0.344 & 125 \\
\hline
\end{tabular}


Evaluation of a New Pinch

Resistance Test Method

Table 4. Comparison of existing and new methods for detecting oxide on AR and FA tubing using 3/32" radius electrodes resistance measured across electrodes.

\begin{tabular}{|c|c|c|c|}
\hline Sample & Volts (V) & $\begin{array}{l}\text { Resistance } \\
\quad(\mathrm{m} \Omega)\end{array}$ & $\begin{array}{l}\text { Current } \\
\text { (Amps) }\end{array}$ \\
\hline AR Ox A, Ex & 0.00878 & 3.682 & 2.385 \\
\hline $\begin{array}{l}\text { AR Ox A, } \\
\text { New }\end{array}$ & 0.5269 & 0.4626 & 1139 \\
\hline AR Ox B, Ex & 0.00868 & 3.637 & 2.386 \\
\hline AR Ox B, New & 0.5482 & 0.4759 & 1152 \\
\hline $\mathrm{AR} \mathrm{Cl} \mathrm{A,} \mathrm{Ex}$ & 0.00867 & 3.636 & 2.385 \\
\hline AR Cl A, New & 0.5441 & 0.4485 & 1213.1 \\
\hline AR $\Delta \mathrm{R}$ & & $\begin{array}{ll}\text { New } & 0.02075 \\
\text { Ex } & 0.02350\end{array}$ & \\
\hline AR $\% \mathrm{R}$ & & $\begin{array}{ll}\text { New } & 4.626533 \\
\text { Ex } & 0.507940 \\
\end{array}$ & \\
\hline $\mathrm{FA}, \mathrm{Ox}, \mathrm{Ex}$ & 0.00865 & 3.627 & 2.384 \\
\hline FA, Ox, New & 0.4865 & 0.3894 & 1249.3 \\
\hline $\mathrm{FA}, \mathrm{Cl}, \mathrm{Ex}$ & 0.00866 & 3.639 & 2.379 \\
\hline $\mathrm{FA}, \mathrm{Cl}, \mathrm{New}$ & 0.5172 & 0.4204 & 1230.3 \\
\hline $\mathrm{FA}, \Delta \mathrm{R}$ & & $\begin{array}{l}-0.031 \\
-0.012\end{array}$ & \\
\hline $\mathrm{FA}, \% \mathrm{R}$ & & $\begin{array}{ll}\text { New } & -5.93581 \\
\text { Ex } & -0.3\end{array}$ & \\
\hline
\end{tabular}

Note: The abbreviations are as follows:

$\mathrm{AR}=$ As-received

$\mathrm{FA}=$ Fully Annealed

$\mathrm{Cl}=$ Clean

$\mathrm{Ox}=$ with light golden Oxide layer

$\mathrm{R}=$ Resistance

$\mathrm{A}=\operatorname{Lot} \mathrm{A}$

$\mathrm{B}=\operatorname{Lot} \mathrm{B}$

$\mathrm{Ex}=$ Existing resistance test method

New $=$ Medar controlled resistance test method 
Evaluation of a New Pinch

Resistance Test Method

Table 5. Effect of cold work on resistance as determined by new and existing methods.

\begin{tabular}{|c|c|c|c|}
\hline $\begin{array}{c}\text { Condition, } \\
\text { (for all } \mathrm{TC}, \mathrm{TE}, \mathrm{Cl}, \mathrm{C} \text { ) }\end{array}$ & $\begin{array}{l}\text { Volts } \\
\text { (V) }\end{array}$ & $\begin{array}{c}\text { Resistance } \\
(\mathrm{m} \Omega)\end{array}$ & $\begin{array}{l}\text { Current } \\
\text { (Amps) }\end{array}$ \\
\hline FA, Ex & 0.00866 & 3.639 & 2.379 \\
\hline FA, New & 0.5172 & 0.4204 & 1230.3 \\
\hline $\mathrm{PA}, \mathrm{Ex}$ & 0.00864 & 3.63 & 2.381 \\
\hline PA, New & 0.5377 & 0.4445 & 1209.5 \\
\hline $\mathrm{AR}, \mathrm{Ex}$ & 0.00867 & 3.636 & 2.385 \\
\hline AR, New & 0.5441 & 0.4485 & 1213.1 \\
\hline PA-FA & & 0.0241 & Old -0.009 \\
\hline AR-PA & & 0.004 & Old 0.006 \\
\hline AR-FA & & 0.0281 & Old -0.003 \\
\hline$\% \mathrm{PA}-\mathrm{FA}$ & & New 5.42182 & \\
\hline$\% \mathrm{AR}-\mathrm{PA}$ & & New 0.89186 & \\
\hline$\% \mathrm{AR}-\mathrm{FA}$ & & $\begin{array}{ll}\text { New } & 6.26533\end{array}$ & \\
\hline
\end{tabular}

Note: The abbreviations are as follows:

$\mathrm{TC}=$ Tight Conductor

$\mathrm{TE}=$ Tight Electrode

$\mathrm{Cl}=$ Clean

$\mathrm{C}=$ measured between electrode and conductor

$\mathrm{FA}=$ fully Annealed

PA $=$ Partially Annealed

$\mathrm{AR}=$ As-received

$\mathrm{Ex}=$ Existing resistance test method

New $=$ Medar controlled resistance test method 
Evaluation of a New Pinch

Resistance Test Method

Table 6. Comparison of existing and new methods for detecting loose electrodes and conductors measured across the electrodes and between an electrode and the front conductor, fully annealed oxidized tubing.

\begin{tabular}{|c|c|c|c|}
\hline $\begin{array}{c}\text { Condition, } \\
\text { On electrodes }\end{array}$ & $\begin{array}{c}\text { Voltage } \\
\text { (V) }\end{array}$ & $\begin{array}{c}\text { Resistance } \\
(\mathrm{m} \Omega)\end{array}$ & $\begin{array}{l}\text { Current } \\
\text { (Amps) }\end{array}$ \\
\hline LC, LE, Ex & 0.00836 & 3.63 & 2.383 \\
\hline LC, LE, New & 0.3302 & 0.2674 & 1234.6 \\
\hline LC, TE, Ex & 0.00862 & 3.614 & 2.385 \\
\hline LC, TE, New & 0.3279 & 0.2676 & 1225.6 \\
\hline TC, LE, Ex & 0.00863 & 3.621 & 3.621 \\
\hline TC, LE, New & 0.3373 & 0.2707 & 1246 \\
\hline TC, TE, Ex & 0.00867 & 3.638 & 3.383 \\
\hline TC, TE, New & 0.3397 & 0.2708 & 1254.5 \\
\hline$\Delta \mathrm{R} \mathrm{TC} / \mathrm{LC}$ & $\begin{array}{l}\text { New } \\
\text { Ex }\end{array}$ & $\begin{array}{l}-0.0033 \\
-0.0075 \\
\end{array}$ & \\
\hline$\% \mathrm{R}$ change & $\begin{array}{c}\text { New } \\
\text { Ex }\end{array}$ & $\begin{array}{c}-1.2 \\
-0.05 \\
\end{array}$ & \\
\hline LC, LE, Ex & 0.00871 & 3.654 & 2.384 \\
\hline LC, LE, New & 0.5499 & 0.4589 & 1198.1 \\
\hline LC, TE, Ex & 0.00869 & 3.649 & 2.383 \\
\hline LC, TE, New & 0.5554 & 0.4531 & 1225.7 \\
\hline TC, LE, Ex & 0.00862 & 3.62 & 2.3807 \\
\hline TC, LE, New & 0.4879 & 0.3898 & 1251.6 \\
\hline TC, TE, Ex & 0.00865 & 3.627 & 2.384 \\
\hline TC, TE, New & 0.4865 & 0.3894 & 1249.3 \\
\hline$\Delta \mathrm{R} \mathrm{TC} / \mathrm{LC}$ & $\begin{array}{l}\text { New } \\
\text { Ex }\end{array}$ & $\begin{array}{c}0.0691 \\
0.028\end{array}$ & \\
\hline$\% \mathrm{R}$ change & $\begin{array}{l}\text { New } \\
\text { Ex }\end{array}$ & $\begin{array}{c}17.1 \\
0.2\end{array}$ & \\
\hline
\end{tabular}

Note: Abbreviations are as follows:

$\mathrm{TC}=$ Tight Conductor,

$\mathrm{LC}=$ Loose Conductor,

$\mathrm{TE}=$ Tight Electrode,

LE $=$ Loose Electrode

$\mathrm{R}=$ Resistance

$\mathrm{Ex}=$ Existing resistance test method

New $=$ Medar controlled resistance test method 
Table 7. Effect of drill rod in center of tube.

\begin{tabular}{|c|c|c|c|}
\hline $\begin{array}{c}\text { Condition, } \\
\text { On Electrodes }\end{array}$ & Volts (V) & Resistance (m $\Omega)$ & Current (Amps) \\
\hline TC, TE, Cl, Bl, Ex & 0.00867 & 3.636 & 2.385 \\
\hline TC, TE, Cl, Bl, New & 0.5441 & 0.4485 & 1213.1 \\
\hline TC, TE, Cl, Rod, Ex & 0.00868 & 3.64 & 2.384 \\
\hline TC, TE, Cl, Rod, New & 0.4737 & 0.4056 & 1168 \\
\hline$\Delta$ R (Rod - B1) & New & -0.0429 & \\
\hline$\Delta$ R (\%) & Ex & 0.004 & \\
\hline & Ex & -9.5 & \\
& & 0.1 & \\
\hline
\end{tabular}

Note: Abbreviations are as follows:

$\mathrm{TC}=$ Tight Conductor

$\mathrm{TE}=$ Tight Electrode

$\mathrm{Cl}=$ Clean

$\mathrm{Bl}=$ Blank (no rod $)$

Rod $=$ rod in center of tube

$\mathrm{Ex}=$ Existing resistance test method

New $=$ Medar controlled resistance test method 


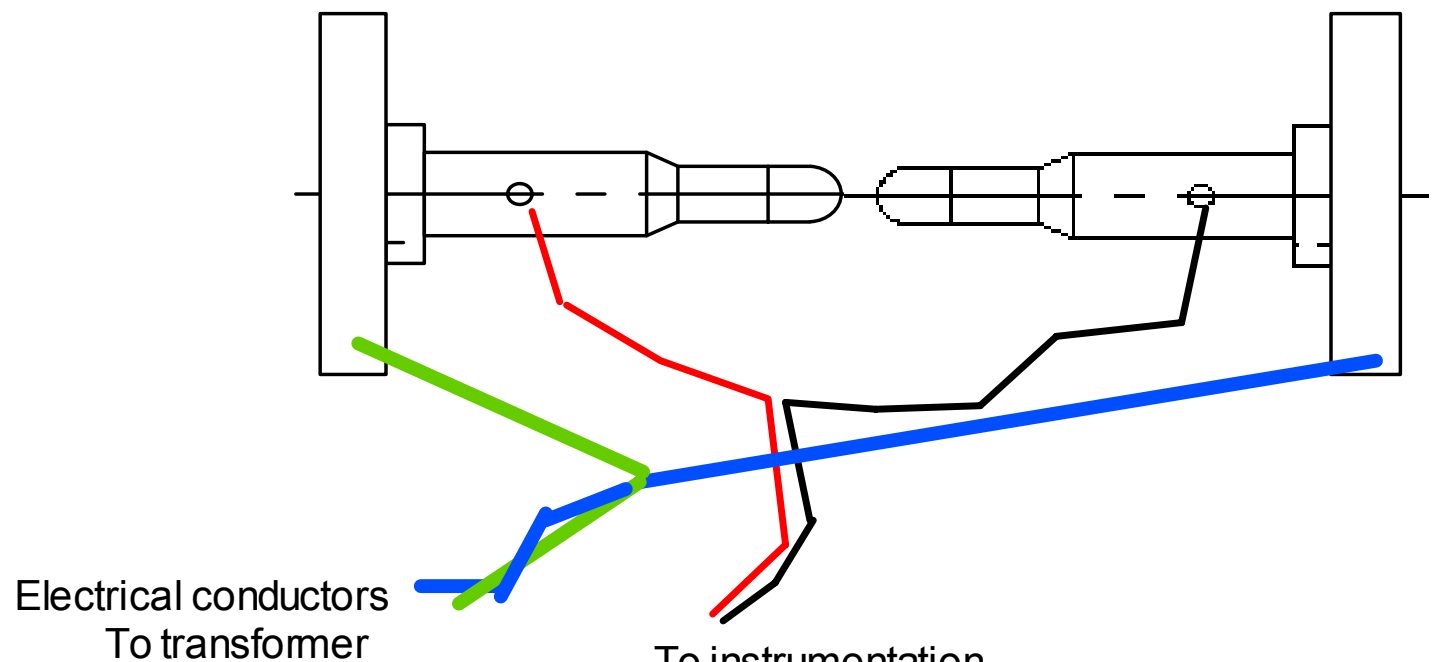

To transformer

To instrumentation

(a)

Placement of probes on an electrode and the conductor

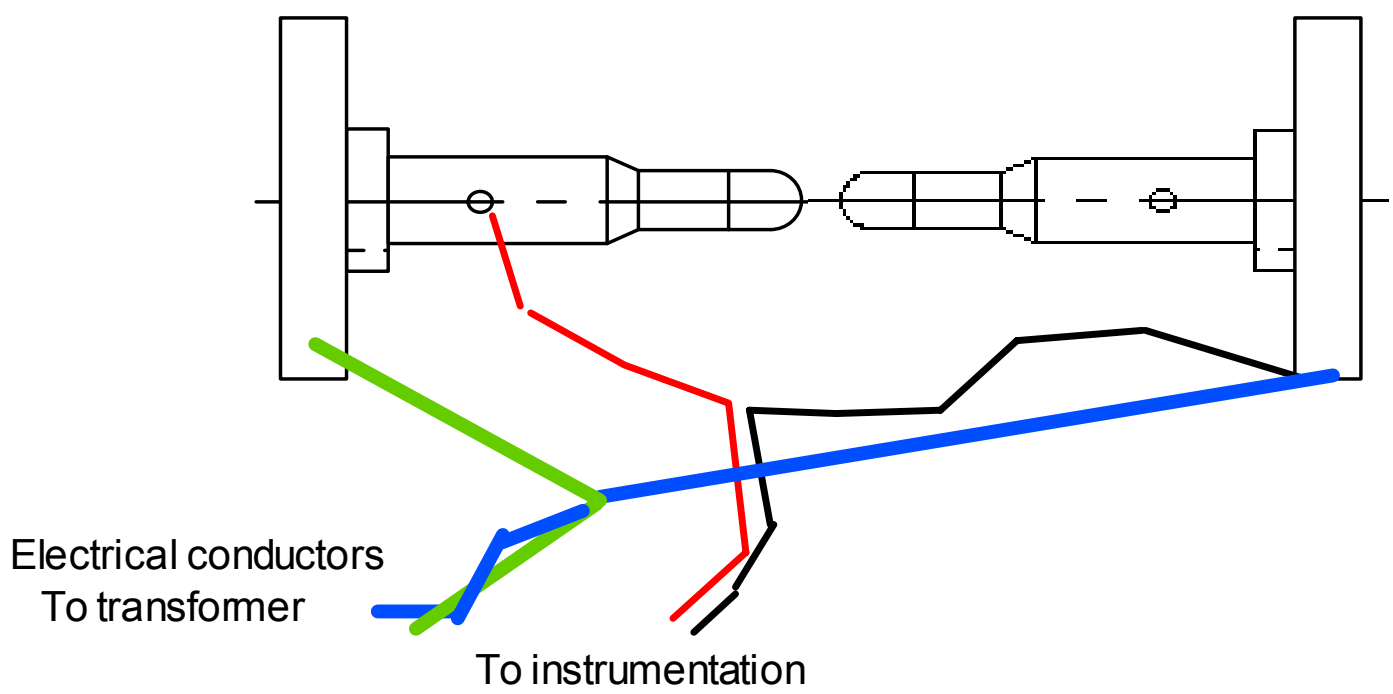

(b)

Figure 1. Location of probes for measuring voltage (a) across the electrodes and (b) across an electrode and a conductor. 


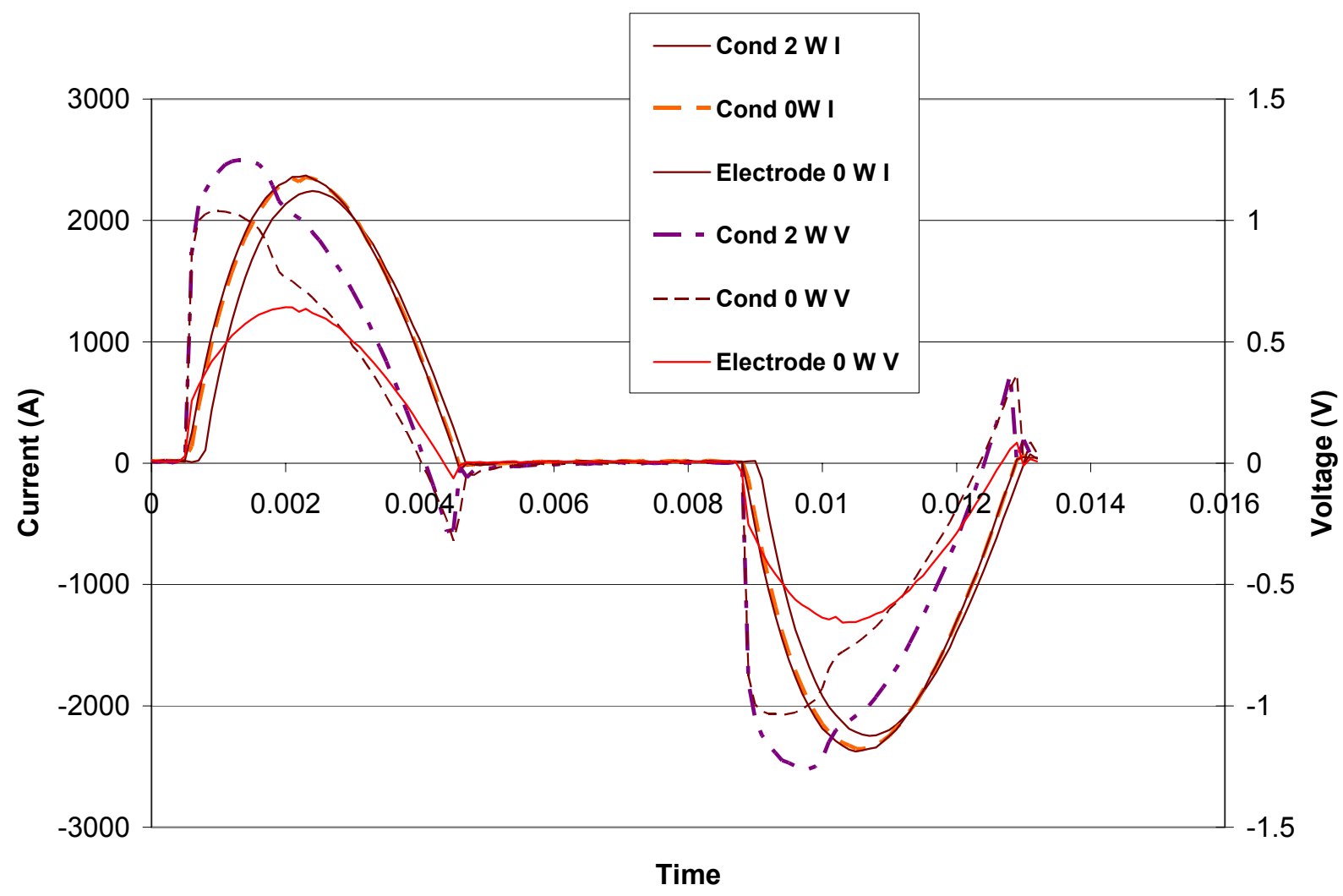

Figure 2. Current - voltage data for new method with probes on electrodes, on conductor and with two "resistors". 


\section{Medar Excited Resistance Data}

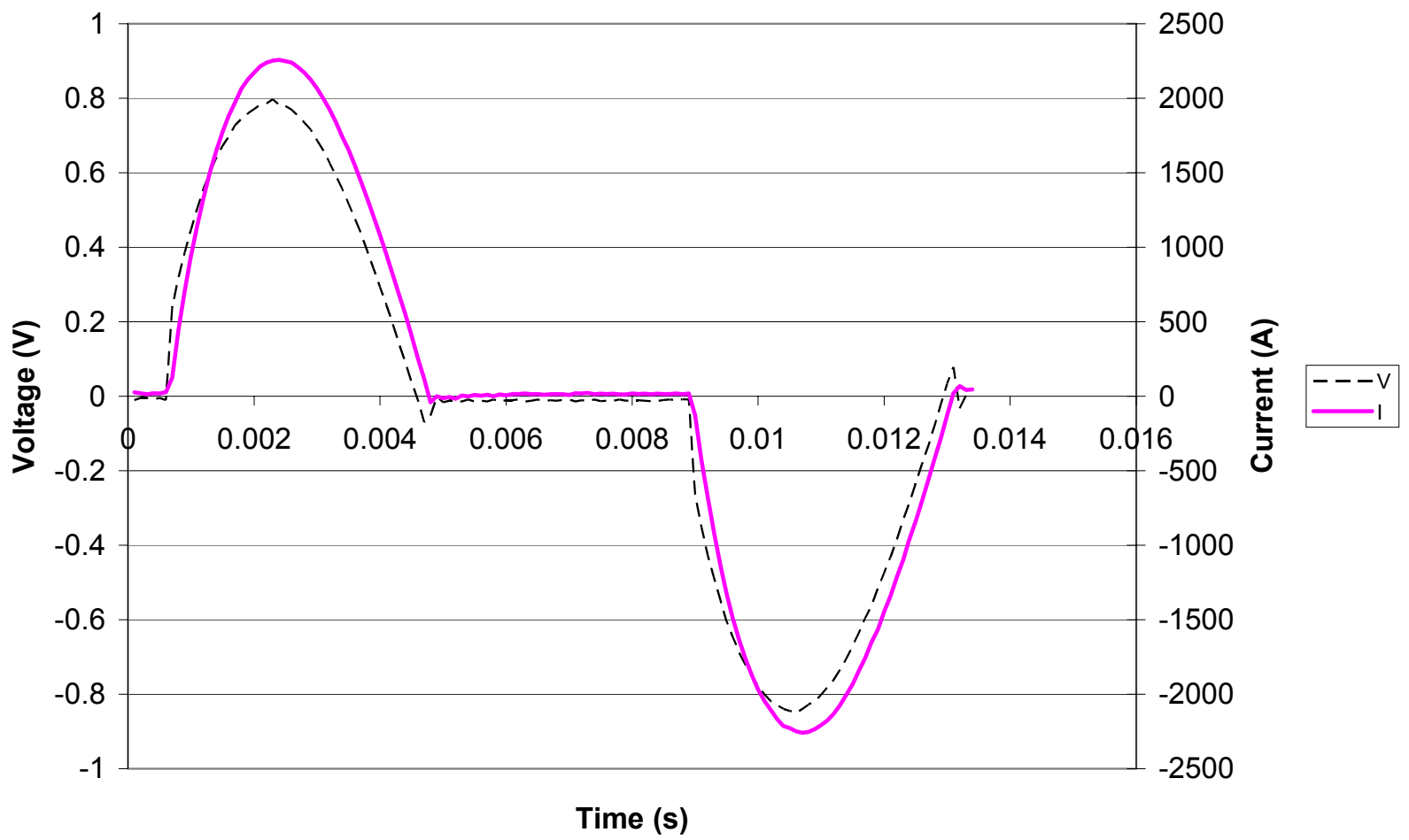

Figure 3. Typical electrical signal of new resistance test method showing the voltage and current for probes on the electrodes. 


\section{Existing Resistance Test}

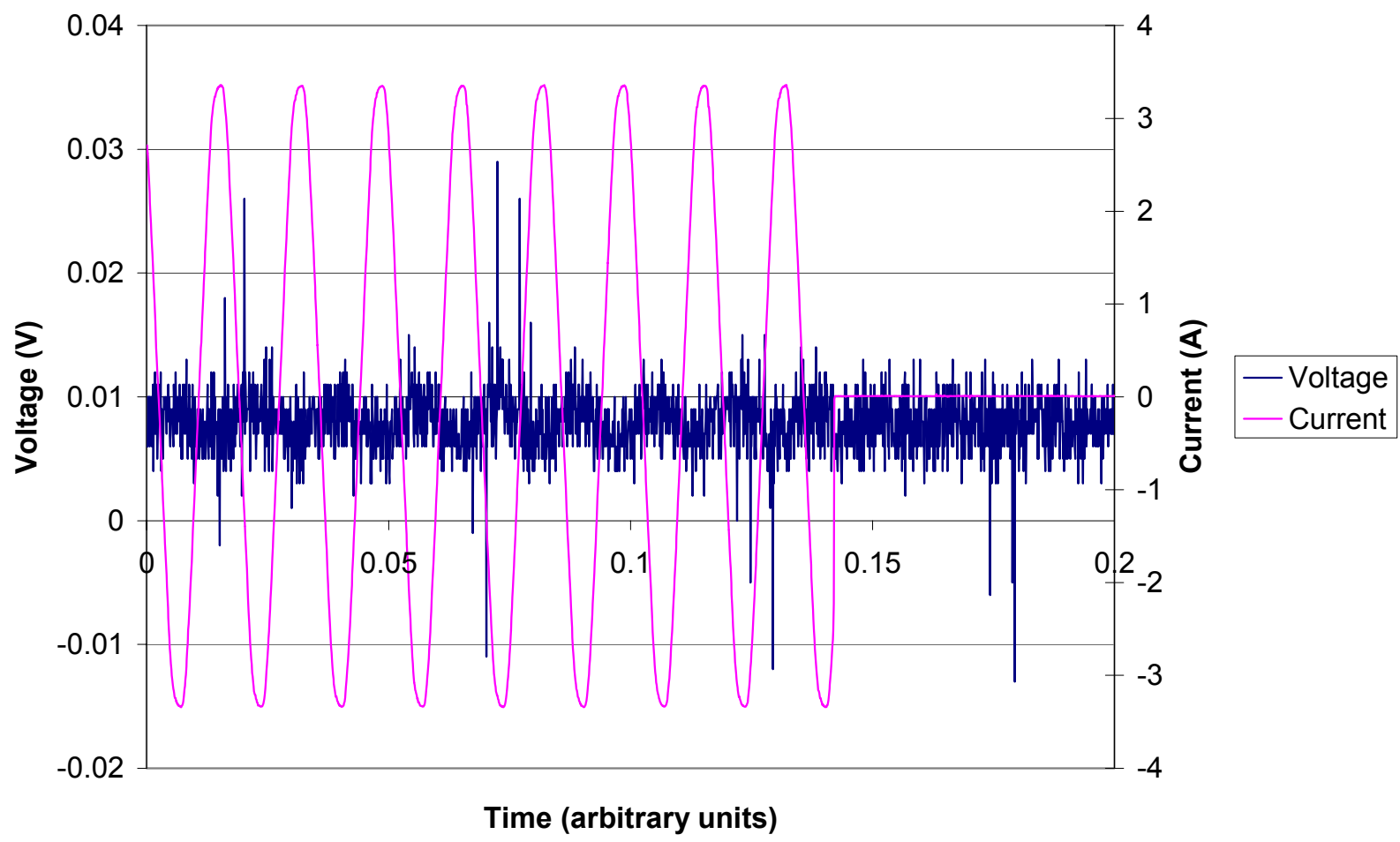

Figure 4. Typical electrical signal of existing resistance test method showing the voltage and current for probes on the electrodes. 
Evaluation of a New Pinch

WSRC-TR-2005-00437

Resistance Test Method

Distribution

R. Rabun

246-H

B. West

246-H

S. R. Howard

S.L. West

old production building

P.S. Korinko

SRNL

S.H. Malene

SRNL

G.J. McKinney

730-A

E.A. Clark

730-A

J.M Tarpley

SRNL

G.H. Fisher, Jr

730-A

J. Cordaro

$723-\mathrm{A}$ 